\title{
The future of dentistry
}

\section{part 1: NHS}

\section{Dr Catherine Rutland}

Clinical Director, Denplan, on how she sees the future of NHS dentistry

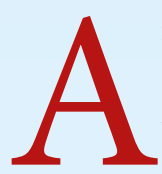

fter a year of such upheaval in dentistry and healthcare services more widely, this is the first of a series of three articles looking at the different impacts of funding mechanisms on NHS, mixed and private practice. It can be easy to think that the way a service is paid for just influences the finances of a practice, yet in my experience that funding mechanism affects everything about a practice and those wider consequences cannot be ignored.

The COVID-19 pandemic has put enormous strain on healthcare provision across the UK and the NHS has struggled to cope with the demands placed on it by its conversion from the National Health Service to the 'COVID-19 Health Service.' This dramatic change in purpose - concentrating resources on pandemic response while limiting patient access to regular health services - as we well know, has had a significant impact on patient access over the last twelve months.

Indeed, as has been observed by Macmillan Cancer Support, the impact on Oncology alone has resulted in an estimated 50,000 missed cancer diagnosis since March $2020 .{ }^{1}$ Likewise with dentistry, some 19 million fewer dental appointments have been carried out compared to the same period the year previously. ${ }^{2}$ These figures demonstrate that across the health system we emerge from the pandemic with unprecedented backlogs in patient appointments and medical procedures. For dentistry, and in particular NHS dental practices, the extra burden created by the pandemic situation has further worsened an already deteriorating and, in my view, untenable landscape.

There are approximately 12,500 dental practices across the UK, with an estimated $40 \%$ of these being wholly or almost completely NHS practices. For these practices, any alteration in funding or consideration of NHS contract changes, regardless of jurisdiction has huge significance both for themselves, their patients and the wider dental sector. With $77 \%$ of predominantly NHS dentists planning to leave NHS dentistry within the next five years, ${ }^{3}$ we have to ask the reasons for their views and what the future of NHS dentistry will look like going forward.

One key contributing factor to dentists leaving NHS practice has been the rising levels of stress and poor mental health associated with working in the profession. Poor mental health and wellbeing has been an ongoing issue in the dental sector for many years long before the advent of COVID-19 and it has been deteriorating for many dentists attempting to fulfil their general dental contracts for a number of years. In recent years the BDA has conducted a number of qualitative research studies regarding mental health in the dental profession and stress, burnout and anxiety featured as the top three welfare issues facing dentists. ${ }^{4}$ For NHS dentists their working conditions and environment and the concern over how they are funded, through all jurisdictions, all contribute to a deteriorating mental health picture. This then impacts the teams they work with and at a time when recruitment is an increasing concern has potential long-term impacts for the profession.

The onset of the COVID-19 pandemic and resulting pandemic restrictions placed on dental practices has worsened the already poor state of mental health in dentistry. A survey conducted in 2020 by Dental Protection discovered that mental health has deteriorated during the pandemic amongst dentists $-45 \%$ of UK dentists feel their mental wellbeing has deteriorated, while almost half feel pessimistic about the future $(48 \%)^{5}$

Added to this is the workloads that dental teams are expected to meet and how this impacts their wider quality of life through their work-life balance. Dentistry can be an isolated profession and if your work life balance is then out of kilter, it places a huge strain on all of the team. So it's no surprise that many dental practitioners are moving away from NHS dentistry and are moving over to the private sector full-time.

Of course, the issue that exacerbates these trends in England is the general dental contract and its accompanying UDAs. In the other jurisdictions, despite different contract types, morale is no better, and in some worse. But the contract itself is proving a significant factor in dental professionals leaving NHS practice in England with the blunt instrument of 'clawback' and strict regulation of UDAs restricting them from delivering patient care as they see best and forcing them to often work unsociably long hours to fulfil targets, with the knock-on effects moving into their personal lives.

As NHS dentists struggle to cope with the pandemic backlog of patient need, the Government has recently put forward its Integration and Innovation white paper on the future of the healthcare system in England.

The white paper comes at a significant moment of transition for dentistry. It envisions a more integrated health system based around Integrated Care Systems (ICS), 
the wider adoption of digital technology in healthcare - from telemedicine to wearable health monitoring tech - and a greater emphasis on preventive healthcare building upon the 2019 prevention green paper ${ }^{6}$ and the NHS Long Term Plan. ${ }^{7}$ While there is a welcome proposal to mandate the fluoridation of drinking water in local areas in the white paper, there is nevertheless a concerning lack of acknowledgement of the vital role dentists play in preventive health and wellbeing.

While water fluoridation is a useful tool in improving public health, the role of local dental practices - NHS, mixed and private - in improving community oral health must not be overlooked. Combined with a fluoridation policy, dentists can support the shift in public health policy from just treatment to prevention through their unique position to identify dietary, lifestyle and chronic health conditions before ill health develops.

Recently, Government ministers have spoken of their ambition to see dental practices performing a greater role in preventive health through practices delivering a wider array of services, such as, monitoring of chronic health conditions like diabetes, early diagnosis of conditions such as mouth cancer and the dispensation of general health advice. ${ }^{8}$ However, without further detail and clarity from DHSC, dentists risk being isolated and underutilised as they have been in previous public health reform initiatives. And of course, there is always the question of how this would be remunerated.

The migration of dental professionals from NHS practice, and the isolation of the dental profession from public health policy, risk further entrenching and worsening oral health inequalities. Even before the pandemic and the CDO-mandated closure of practices for routine care last year, the state of oral health in the UK has increasingly become a bifurcated picture of growing divergence between those with access to dental care and those, particularly from our most deprived communities, who are unable to do so for a myriad of reasons.

As Simplyhealth's 2019 Consumer Oral Health Survey identified, one in five children are suffering from dental caries and one in ten children have missed a full day of schooling due to poor oral health. ${ }^{9}$ Indeed, this is underscored by PHE data showing that tooth decay is still the most common reason for hospital admissions for 6-10-yearolds with admissions for tooth extraction in the most deprived communities nearly four times that of those living in the most affluent communities. ${ }^{10}$ This is before we even consider the impact of poor oral health on wider health outcomes such as heart disease, diabetes and strokes, and the additional burden this places on the NHS. It deeply saddens me that well over 25 years after I was a Senior House Officer in Newcastle carrying out GA full mouth clearances on three-yearolds that so many children are still having to go through the same procedure.

It is therefore vital that to address burgeoning oral health inequalities that we address the future of NHS dentistry. As I have stated previously, dentistry needs to be more integrated into the wider healthcare system, there needs to be greater recognition of the role dentistry can play in the preventive health agenda, and the dental contract needs to be more flexible to reduce the pressures on dentists that exacerbate stress and mental health issues.

However, we also need to recognise that NHS dentistry alone cannot manage the burden of growing demand. The shift must be towards a more preventive health model and there must be recognition that the universal basis of NHS dentistry is unsustainable without significant investment from central government or a more targeted approach to those communities most at need. With $66 \%$ of regular attending NHS patients saying they would consider paying privately for at least part of their dental care, ${ }^{11}$ in my view our focus should shift to preserving a core NHS dentistry service for those genuinely unable to access non-NHS dentistry and preventive oral health measures such as water fluoridation and child oral health in education settings.

\section{References}

1. Macmillan Cancer Support. The Forgotten ' $C$ '? The impact of Covid-19 on cancer care. Oct 2020. Online information available at: www.macmillan. org.uk/assets/forgotten-c-impact-of-covid-19on-cancer-care.pdf (Accessed April 2021).

2. British Dental Association. Capital funding: the way forward on fallow time. Nov 2020. Online information available online at: https://bda. org/news-centre/blog/Pages/Capital-fundingThe-way-forward-on-fallow-time.aspx (Accessed April 2021).

3. Dentistry. Almost half of NHS dentists want to go private. Mar 2020. Online information available at: https://dentistry.co.uk/2020/03/02/almosthalf-nhs-dentists-want-private/ (Accessed April 2021).

4. British Dental Association. The Mental Health and Well-being of UK Dentists: A Qualitative Study. Aug 2017. Online information available at: https://bda.org/about-the-bda/campaigns/ Documents/The\%20Mental\%20Health\%20
and\%20Well-being\%20of\%20UK\%20Dentists. pdf (Accessed March 2020).

5. Dental Protection. COVID-19: Half of UK dentists feel pessimistic about the future. Oct 2020. Online information available at: www. dentalprotection.org/uk/articles/covid-19-halfof-uk-dentists-feel-pessimistic-about-the-future (Accessed April 2021)

6. Department of Health and Social Care Advancing our health: prevention in the 2020s. Available online at: https://assets.publishing. service.gov.uk/government/uploads/system/ uploads/attachment data/file/819766/ advancing-our-health-prevention-in-the-2020saccessible.pdf (Accessed May 2021).

7. Department of Health and Social Care. NHS Long-Term Plan. Jan 2019. Online information available at: www.longtermplan.nhs.uk/ wp-content/uploads/2019/08/nhs-long-termplan-version-1.2.pdf (Accessed March 2021).

8. Hansard. COVID-19: dental services. Jan 2021 Online information available at: https:// hansard.parliament.uk/commons/2021-01-14/ debates/15169201-A026-433C-9105D5007E11CF88/Covid-19DentalServices (Accessed January 2021).

9. Denplan. Consumer Oral Health Survey 2019. Simplyhealth, 2019

10. Public Health England. Hospital tooth extractions 2016 to 2020, Dec 2020. Online information available at: https://assets.publishing.service. gov.uk/government/uploads/system/uploads/ attachment_data/file/941080/Tidy_data.csv/ preview (Accessed March 2021).

11. Denplan, Consumer Oral Health Survey 2019 Simplyhealth, 2019

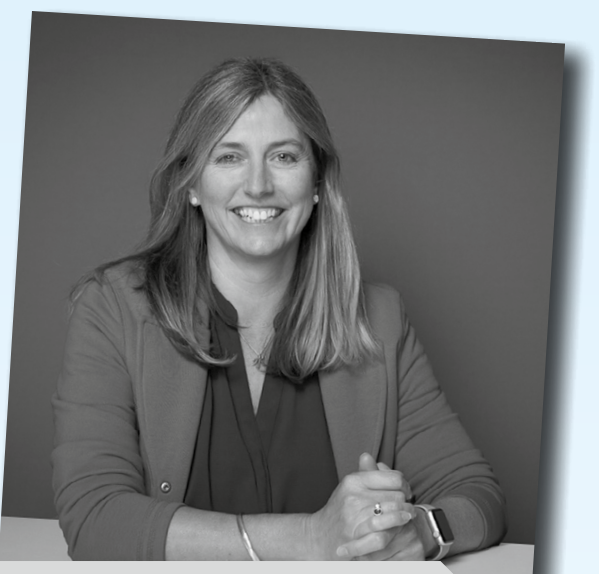

\section{Author bio}

After qualifying as a dentist from Leeds University in 1992 and doing a year as a House Officer, Catherine worked as a Senior House Officer in Newcastle before settling into general dental practice. Catherine joined Denplan part-time in 2010 and was promoted to her current position in 2019. She has 19 years' experience as a joint partner in a private dental practice in Berkshire, and completed a Masters in Medical Ethics and Law from King's College London in 2013. She is also a certified member of the Institute of Risk Management and completed a Level 7 Certificate in Leadership Mentoring and Coaching in 2016.

https://doi.org/10.1038/s41404-021-0768-6 